\title{
Cobalt Metal-Organic Frameworks Incorporating Redox-Active Tetrathiafulvalene Ligand: Structures and Effect of LLCT within MOF on Photoelectrochemical Properties
}

Miao Jiang, Yi-Gang Weng, Zi-Yao Zhou, Chen-Yi Ge, Qin-Yu Zhu, * and Jie Dai*

College of Chemistry, Chemical Engineering and Materials Science, Soochow University, Suzhou 215123, P. R. China

\section{Characterizations and measurements}

\section{Figures}

Figure S1. The experimental powder XRD patterns and the simulated pattern from the crystal data of compounds $\mathbf{1}-\mathbf{3}$.

Figure S2. 1D Co4-Co5-Co6 chain structure bridged by carboxylate groups of $\mathrm{L}$ in 1.

Figure S3. 2D network of 1 indicating the arrangement of the six cobalt ions linked by carboxylate groups of $\mathrm{L}$ and bpe. Hydrogen atoms and ligand $\mathrm{L}$ except those related coordination atoms are omitted for clarity.

Figure S4. The sketch maps of the planes of parts of bpe and L in $\mathbf{1}$.

Figure S5. Structures of $\mathrm{Co}_{5}$ clusters in this work and previously reports.

Figure S6. Stick representation of the cluster chain in $\mathbf{2}$ along the $a$ axis showing that TTF is located evenly in the four directions of the chain. bpe is omitted except the coordinated nitrogen atoms for clarity.

Figure S7. A part of the packing diagram of 2 showing the $\pi \cdots \pi$ interactions between the TTF moiety and bpe molecule.

Figure S8. (a) An infinite $-\mathrm{Co}-\mathrm{O}-\mathrm{C}-\mathrm{O}-\mathrm{Co}-1-\mathrm{D}$ chain along the $b$ axis constructed by carboxylate bridges of 3. bpa except the coordinated nitrogen atoms and all hydrogen atoms are omitted for clarity; (b) 2-D network structure of 3. L except the coordinated carboxylate groups and all hydrogen atoms are omitted for clarity.

Figure S9. Solid-state ESR spectra of 1 and $\mathbf{2}$ recorded at $120 \mathrm{~K}$.

Figure S10. (a) CV curves of 1 at different scan rates. (b) The integrated area of the $\mathrm{CV}$ curves and the specific capacitances of $\mathbf{1}$ at different scan rates. (c) GCD curves of $\mathbf{1}$ at different current intensities. (d) Variation of specific capacitance of $\mathbf{1}$ with 
applied currents.

Figure S11. (a) CV curves of 2 at different scan rates. (b) The integrated area of the CV curves and the specific capacitances of 2 at different scan rates. (c) GCD curves of $\mathbf{2}$ at different current intensities. (d) Variation of specific capacitance of $\mathbf{2}$ with applied currents.

Figure S12. Curves of the peak currents vs the square roots of scan rates of 1, 2, and 3 for $\mathrm{CV}$ measurements.

Figure S13. The specific capacitances of 1, 2, and $\mathbf{3}$ at different scan rates.

\section{Tables}

Table S1. The mean deviations from the planes of the TTF moiety and bpe, the dihedral angles and the distances between least-squares planes in $\mathbf{1}$ and $\mathbf{2}$.

Table S2. Comparison of Csp values of various Co-MOF materials.

Table S3. Crystal data and structural refinement parameters for compounds 1-3.

\section{Equations}




\section{Characterizations and Measurements}

\section{General Remarks.}

The sodium salt of dimethylthio-tetrathiafulvalene-bicarboxylate $\left(\mathrm{Na}_{2} \mathrm{~L}\right)$ was prepared according to the literature. ${ }^{1}$ All analytically pure reagents were purchased commercially and used without further purification. Elemental analyses $(\mathrm{C}, \mathrm{H}$, and $\mathrm{N})$ were performed using a VARIDEL III elemental analyzer. Solid-state room-temperature optical diffuse reflectance spectra of the microcrystal samples were obtained with a Shimadzu UV-2600 spectrophotometer using $\mathrm{BaSO}_{4}$ as a standard reference. Powder X-ray diffraction (PXRD) data were obtained using a D/MAX-3C X-ray diffraction meter with $\mathrm{CuK} \alpha(\lambda=1.5406 \AA)$ radiation. Cyclic voltammetry (CV) experiments were performed on a CHI650 electrochemistry workstation in a three-electrode system with a Pt plate working electrode, a saturated calomel electrode (SCE) as reference electrode, and Pt wire as the auxiliary electrode. Electron spin resonance (ESR) spectra were carried out at $120 \mathrm{~K}$ and obtained using a Bruker ER-420 spectrometer with a $100 \mathrm{kHz}$ magnetic field in $\mathrm{X}$ band.

\section{X-ray Crystallographic Study.}

The crystal data were collected on a Bruker APEX-II CCD diffractometer for 1 and a Rigaku Mercury CCD diffractometer for $\mathbf{2}$ and $\mathbf{3}$ equipped with graphite monochromated Mo $\operatorname{K\alpha }(\lambda=0.71075 \AA)$ radiation were used to carry out the measurements at $223 \mathrm{~K}$. An absorption correction (multiscan) was applied for all these compounds. The structures were solved by direct methods using SHELXS-16 program and the refinements were performed against $F^{2}$ using SHELXL-16. ${ }^{2}$ Detailed crystal data and structural refinement parameters are listed in Table S3 in the Supporting Information.

\section{Electrode Preparation and Photocurrent Measurement.}

The photoelectrodes of the compounds were prepared by powder coating method. As a typical procedure, the crystals of compounds $(0.005 \mathrm{mmol})$ were ground and pressed uniformly on the ITO glass $(1.0 \times 1.0 \mathrm{~cm}, 8 \Omega / \square)$. A $150 \mathrm{~W}$ high-pressure xenon lamp, located $20 \mathrm{~cm}$ away from the surface of the ITO electrode, was employed 
as a full-wavelength light source. The photocurrent experiments were performed at room temperature on a $\mathrm{CHI} 660 \mathrm{E}$ electrochemistry workstation in a three-electrode system, with the sample coated ITO glass as the working electrode mounted on the window with an area of $0.50 \mathrm{~cm}^{2}$, a Pt wire as auxiliary electrode and a saturated calomel electrode (SCE) as reference electrode. The supporting electrolyte solution was a $0.1 \mathrm{~mol} \cdot \mathrm{L}^{-1}$ sodium sulfate aqueous solution. The lamp was kept on continuously, and a manual shutter was used to block exposure of the sample to the light. The sample was typically irradiated at intervals of $20 \mathrm{~s}$.

\section{Fabrication of the working electrodes and electrochemical measurements.}

The working electrodes were obtained with the following procedure. The compounds as active materials, acetylene black, and a poly(vinylene fluoride) (PVDF) emulsion, were mixed in ethanol at a weight ratio of $75: 15: 10$, and dispersed by ultrasonic treatment for $10 \mathrm{~min}$. The slurry was coated on a nickel foam $(1.0 \times 1.0$ $\mathrm{cm}^{2}$ ) current collector and then pressed and dried under vacuum at $60^{\circ} \mathrm{C}$ for $12 \mathrm{~h}$. The mass of the active loading on the nickel foam was $\sim 3 \mathrm{mg}$. The electrochemical properties of the active material were tested using a CHI660E electrochemical workstation by a conventional three-electrode system with a calomel reference electrode and a platinum counter electrode. The average specific capacitances of the electrodes were calculated based on the $\mathrm{CV}$ curves and the discharge curves, respectively. All of the electrochemical measurements were performed in a $6.0 \mathrm{M}$ $\mathrm{KOH}$ solution at room temperature.

\section{References}

(1) (a) McCullough, R. D.; Petruska, M. A.; Belot, J. A. Tetrahedron 1999, 55, 9979-9998. (b) Hudhomme, P.; Moustarder, S. L.; Durand, C.; Gallego-Planas, N.; Mercier, N.; Blanchard, P.; Levillain, E.; Allain, M.; Gorgues, A.; Riou, A. Chem. Eur. J. 2001, 7, 5070-5083. 
(2) (a) Sheldrick, G. M. SHELXS-97, Program for structure solution; Universität of Göttingen, Göttingen, Germany, 1999. (b) Sheldrick, G. M. Crystal structure refinement with SHELXL. Acta Crystallogr., Sect. C: Struct. Chem. 2015, 71, 3-8. 


\section{Figures}
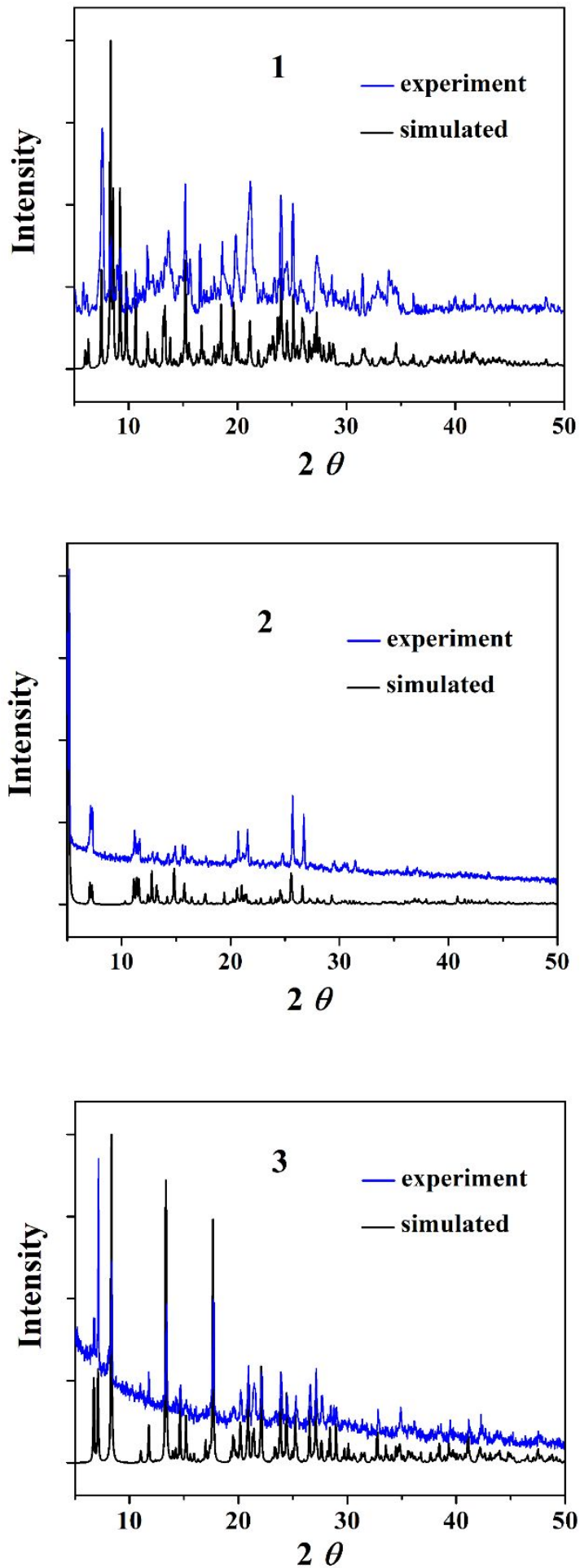

Figure S1. The experimental powder XRD patterns and the simulated pattern from the crystal data of compounds $\mathbf{1}-\mathbf{3}$. 


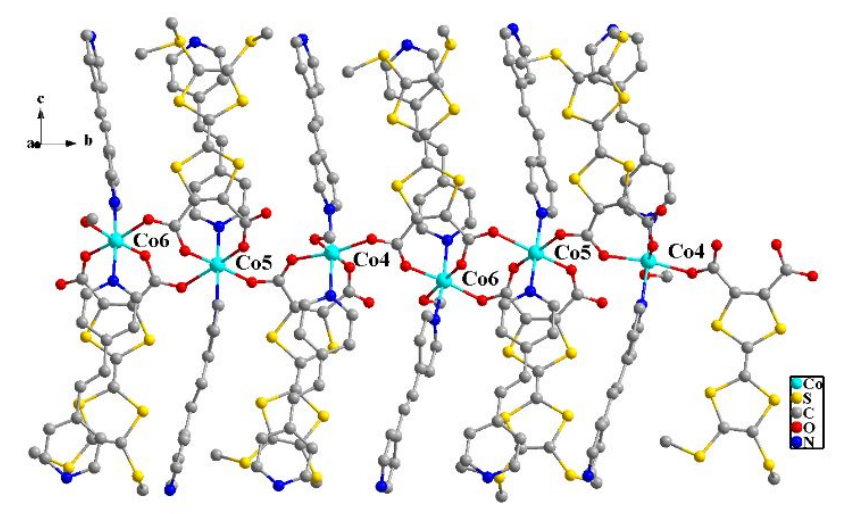

Figure S2. 1D Co4-Co5-Co6 chain structure bridged by carboxylate groups of L in 1.

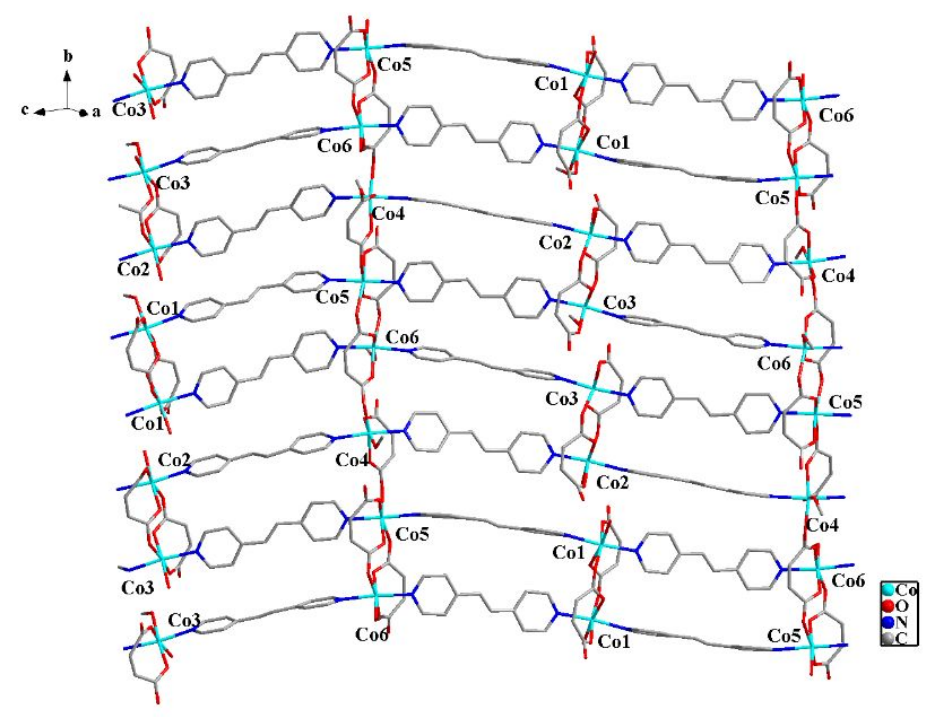

Figure S3. 2D network of 1 indicating the arrangement of the six cobalt ions linked by carboxylate groups of $\mathrm{L}$ and bpe. Hydrogen atoms and ligand $\mathrm{L}$ except those related coordination atoms are omitted for clarity. 


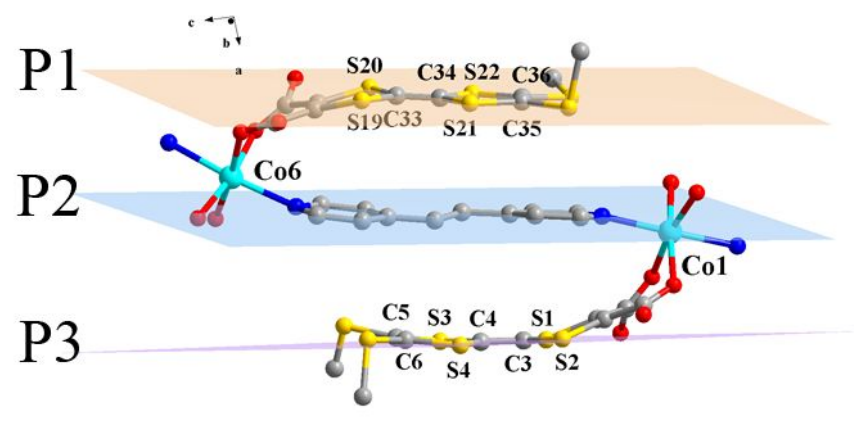

(a)

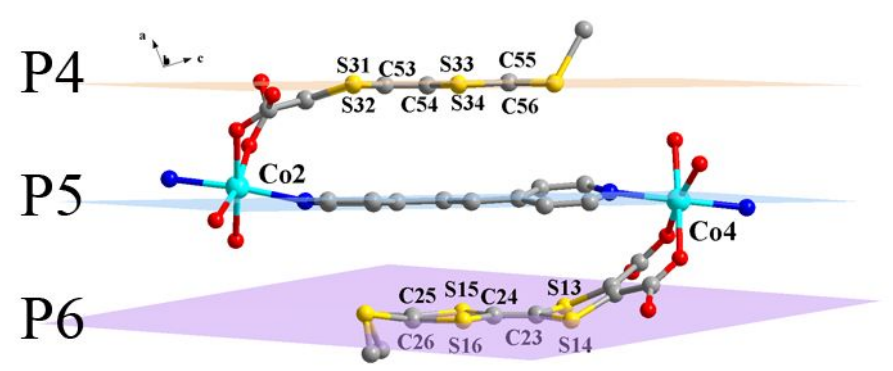

(b)

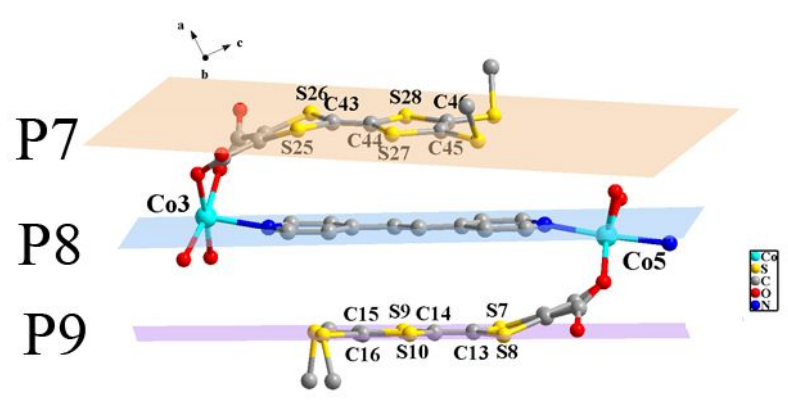

(c)

Figure S4. The sketch maps of the planes of parts of L and bpe in $\mathbf{1 .}$ 


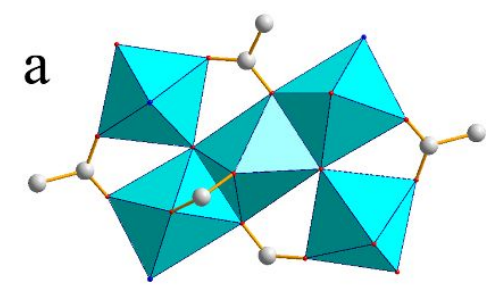

5 Co-oct (this work)

d

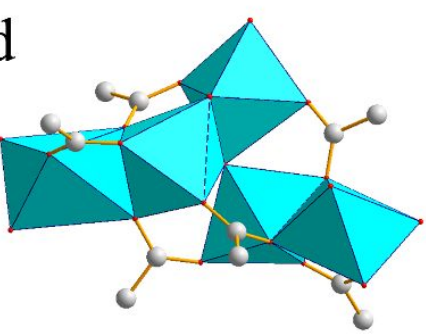

4 Co-oct +1 Co-sp

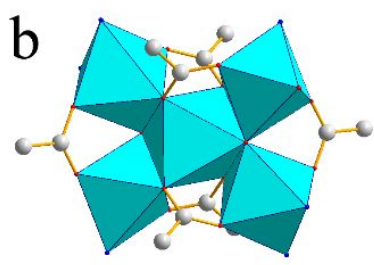

$5 \mathrm{Co}-\mathrm{oct}$

e

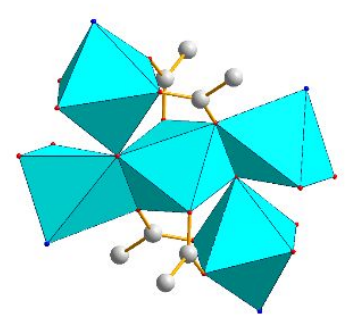

3 Co-oct +2 Co-tbp

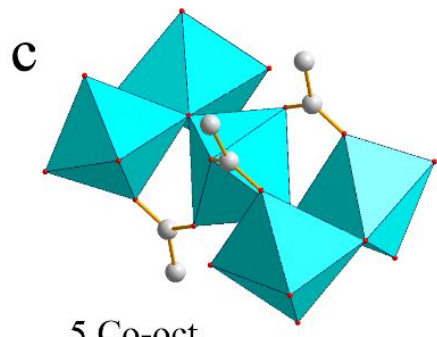

5 Co-oct

f

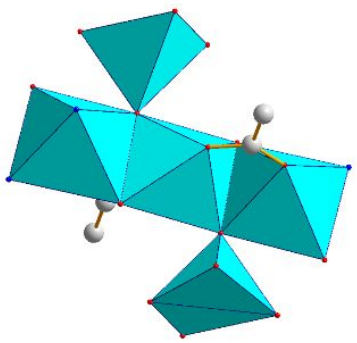

3 Co-oct +2 Co-sp

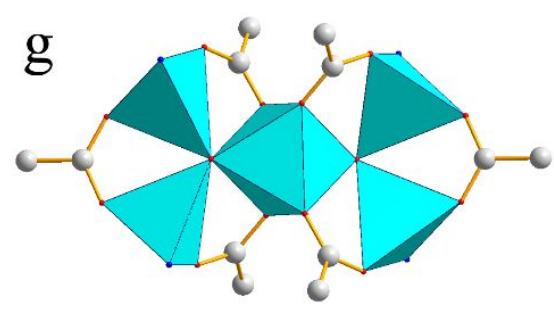

1 Co-oct +4 tetra

$$
\begin{aligned}
\text { oct } & =\text { octahedron } \\
\text { tbp } & =\text { trigonal bipyramid } \\
\mathrm{sp} & =\text { square pyramid } \\
\text { tetra } & =\text { tetrahedron }
\end{aligned}
$$

Figure S5. Structures of $\mathrm{Co}_{5}$ clusters in this work and previously reports.

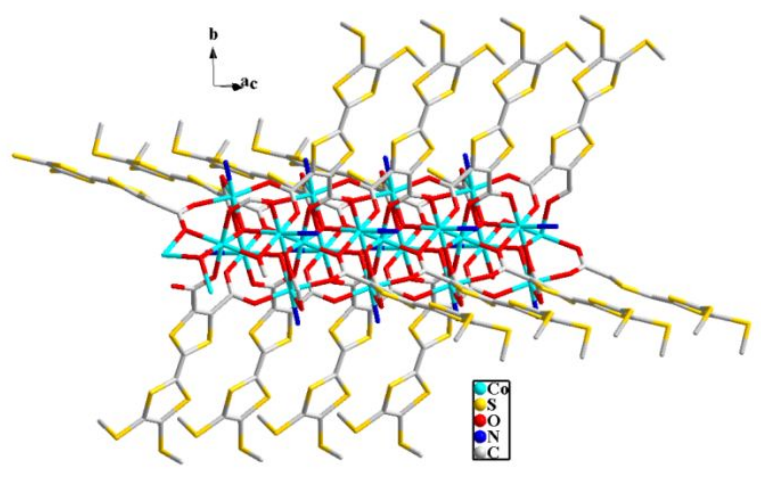

Figure S6. Stick representation of the cluster chain in $\mathbf{2}$ along the $a$ axis showing that TTF is located evenly in the four directions of the chain. bpe is omitted except the coordinated nitrogen atoms for clarity. 


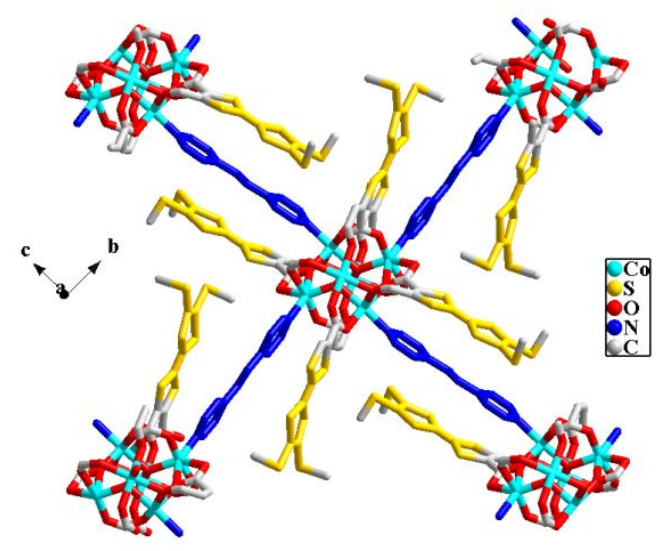

Figure S7. A part of the packing diagram of 2 showing the $\pi^{\cdots} \pi$ interactions between the TTF moiety and bpe molecule. 


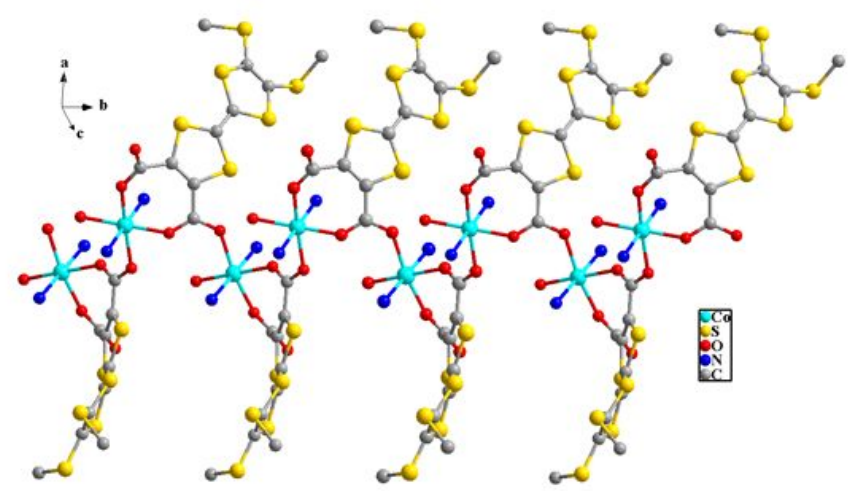

(a)

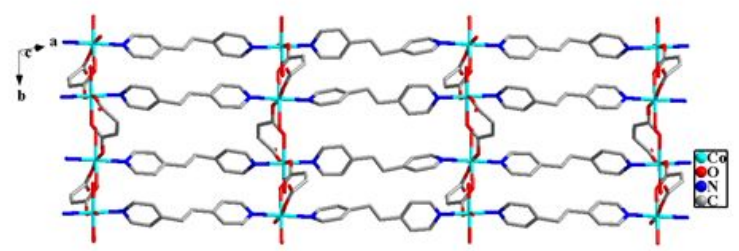

(b)

Figure S8. (a) An infinite $-\mathrm{Co}-\mathrm{O}-\mathrm{C}-\mathrm{O}-\mathrm{Co}-1-\mathrm{D}$ chain along the $b$ axis constructed by carboxylate bridges of 3. bpa except the coordinated nitrogen atoms and all hydrogen atoms are omitted for clarity; (b) 2-D network structure of 3. L except the coordinated carboxylate groups and all hydrogen atoms are omitted for clarity.

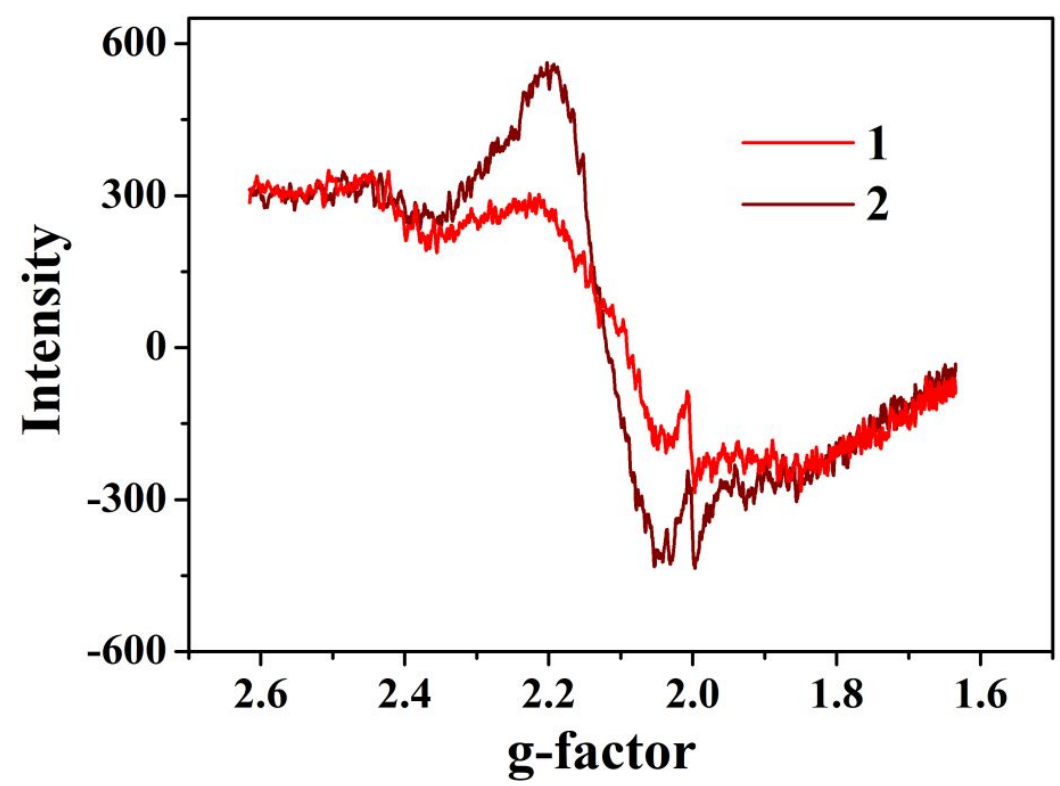

Figure S9. Solid-state ESR spectra of $\mathbf{1}$ and $\mathbf{2}$ recorded at $120 \mathrm{~K}$. 


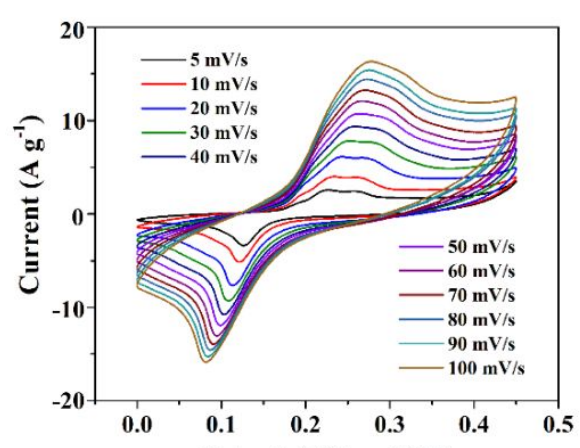

(a)

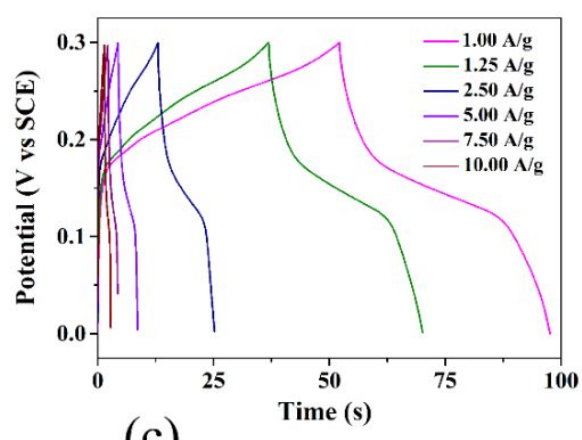

(c)

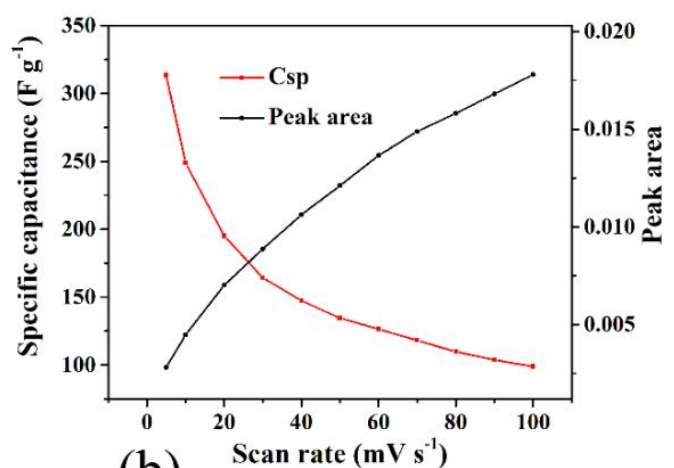

(b)

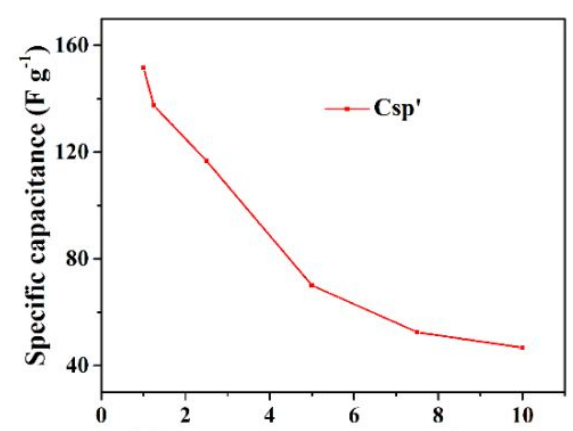

(d) Current density ( $\left.\mathrm{A} \mathrm{g}^{-1}\right)$

Figure S10. (a) CV curves of $\mathbf{1}$ at different scan rates. (b) The integrated area of the $\mathrm{CV}$ curves and the specific capacitances of $\mathbf{1}$ at different scan rates. (c) GCD curves of 1 at different current intensities. (d) Variation of specific capacitance of 1 with applied currents. 


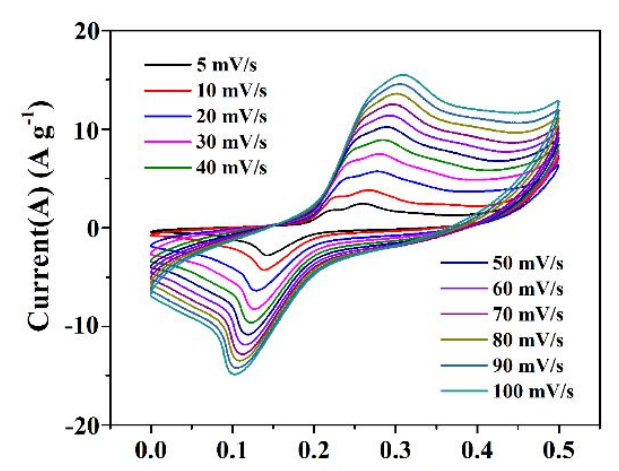

(a)

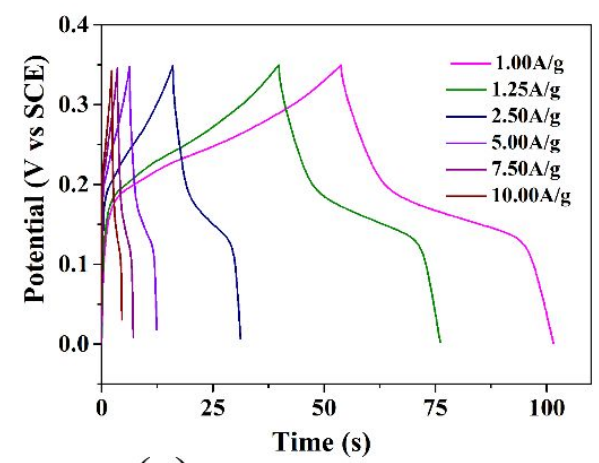

(c)

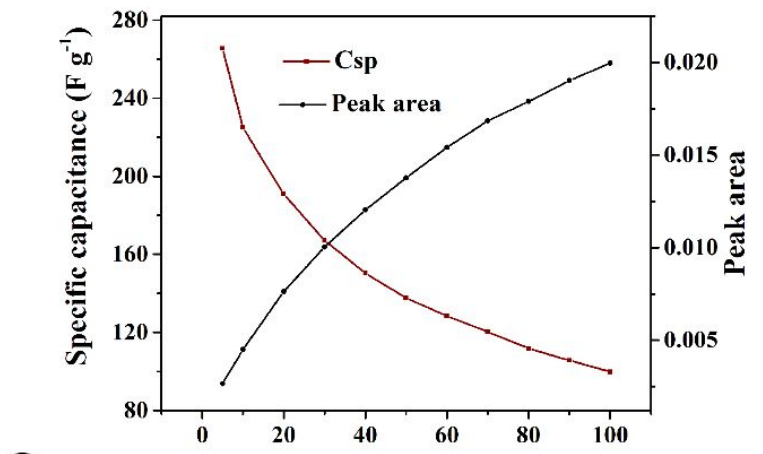

(b) Scan rate $\left(\mathrm{mV} \mathrm{s}^{-1}\right)$

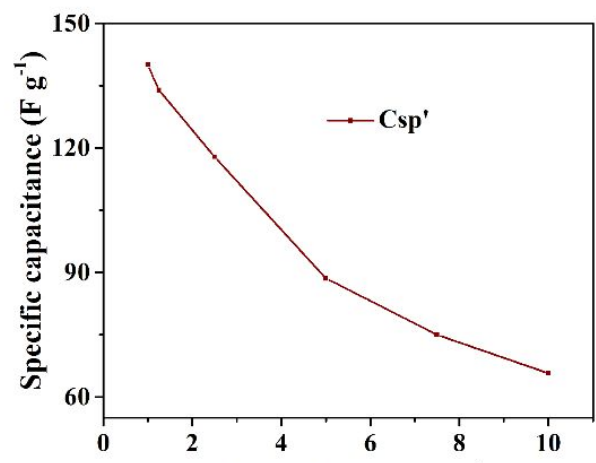

(d) Current density $\left(\mathrm{A} \mathrm{g}^{-1}\right)$

Figure S11. (a) CV curves of $\mathbf{2}$ at different scan rates. (b) The integrated area of the CV curves and the specific capacitances of 2 at different scan rates. (c) GCD curves of 2 at different current intensities. (d) Variation of specific capacitance of 2 with applied currents. 

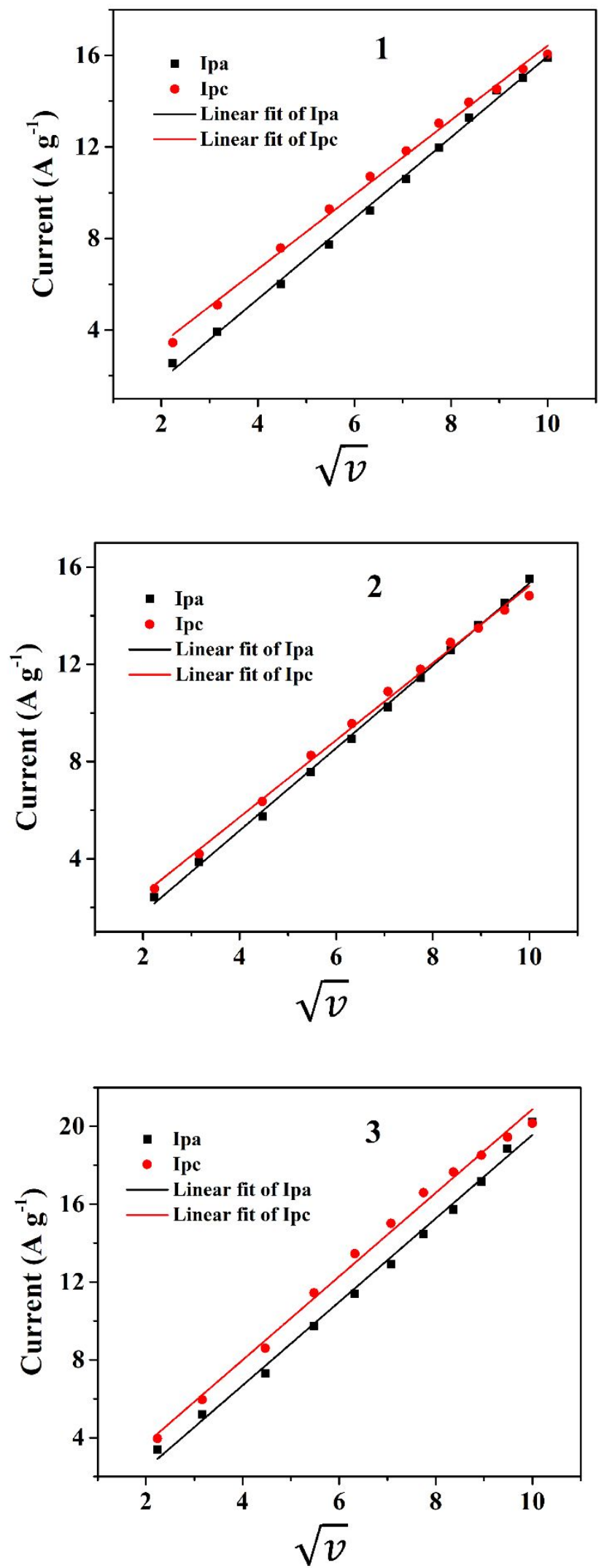

Figure S12. Curves of the peak currents vs the square roots of scan rates of 1, 2, and 3 for CV measurements. 


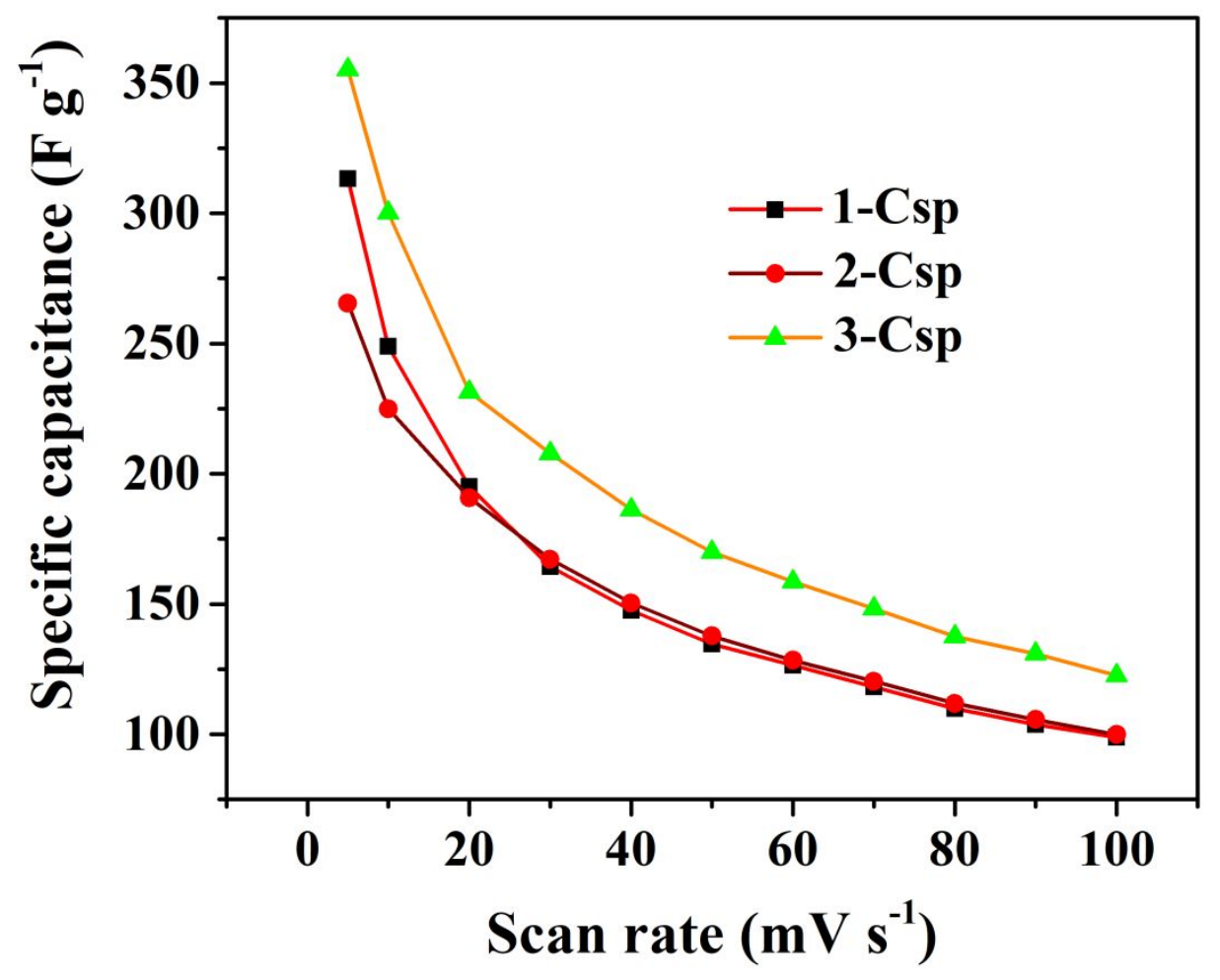

Figure S13. The specific capacitances of 1, 2, and $\mathbf{3}$ at different scan rates. 
Table S1. The mean deviations $(\AA)$ from the plane of the TTF moiety and of bpe, the dihedral angles $\left({ }^{\circ}\right)$ and the distances $(\AA)$ between least-squares planes in $\mathbf{1}$ and $\mathbf{2}$.

\begin{tabular}{|c|c|c|c|c|c|c|}
\hline & \multicolumn{3}{|c|}{ mean deviation $(\AA)$} & $\begin{array}{l}\text { dihedral } \\
\operatorname{angle}\left({ }^{\circ}\right)\end{array}$ & \multicolumn{2}{|c|}{$\begin{array}{l}\text { distance between } \\
\operatorname{planes}(\AA)\end{array}$} \\
\hline \multirow{9}{*}{1} & P1 & $0.0233(0.0057)$ & $\mathrm{P} 1 \wedge \mathrm{P} 2$ & $0.667(131)$ & $\mathrm{P} 1-\mathrm{P} 2$ & 3.70 \\
\hline & $\mathrm{P} 2$ & $0.0701(0.0086)$ & $\mathrm{P} 3^{\wedge} \mathrm{P} 2$ & $6.545(136)$ & P3-P2 & 3.94 \\
\hline & $\mathrm{P} 3$ & $0.0614(0.0064)$ & $\mathrm{P} 1 \wedge \mathrm{P} 3$ & $7.212(62)$ & & \\
\hline & $\mathrm{P} 4$ & $0.0230(0.0066)$ & $\mathrm{P} 4^{\wedge} \mathrm{P} 5$ & $0.575(205)$ & P4-P5 & 3.62 \\
\hline & P5 & $0.0148(0.0092)$ & $\mathrm{P} 6^{\wedge} \mathrm{P} 5$ & $8.427(223)$ & P6-P5 & 3.58 \\
\hline & P6 & $0.0281(0.0076)$ & $\mathrm{P} 4^{\wedge} \mathrm{P} 6$ & $7.959(77)$ & & \\
\hline & P7 & $0.0121(0.0066)$ & $\mathrm{P} 7^{\wedge} \mathrm{P} 8$ & $5.623(151)$ & P7-P8 & 3.53 \\
\hline & P8 & $0.0193(0.0084)$ & $\mathrm{P} 9^{\wedge} \mathrm{P} 8$ & $2.941(138)$ & P9-P8 & 3.56 \\
\hline & P9 & $0.0251(0.0066)$ & $\mathrm{P} 7^{\wedge} \mathrm{P} 9$ & $7.953(69)$ & & \\
\hline \multirow[b]{2}{*}{2} & $\mathrm{P} 1$ & $0.0288(0.0100)$ & & \multirow[b]{2}{*}{$2.037(18)$} & & \multirow[b]{2}{*}{3.63} \\
\hline & $\mathrm{P} 2$ & $0.0452(0.0122)$ & & & & \\
\hline
\end{tabular}

Table S2. Comparison of Csp values of various Co-MOF materials.

\begin{tabular}{lllll}
\hline MOFs & $\mathrm{F} \mathrm{g}^{-1} / \mathrm{mVs}^{-1}$ & $\mathrm{~F} \mathrm{~g}^{-1} / \mathrm{A} \mathrm{g}^{-1}$ & $\mathrm{~F} \mathrm{~g}^{-1} / \mathrm{A} \mathrm{g}^{-1}$ & Refs. \\
\hline$\left[\mathrm{Co}_{2}(\mathrm{OH})_{2} \mathrm{C}_{8} \mathrm{H}_{4} \mathrm{O}_{4}\right]$ & & $2564 / 1$ & $1165 / 20$ & 42 \\
$\mathrm{Co} 8-\mathrm{MOF}-5$ & $3.27 / 25$ & $1.98 / 0.01$ & & 43 \\
$\mathrm{Co-BDC}$ & $131.8 / 10$ & & 44 \\
$\mathrm{Co-NDC}$ & $147.3 / 10$ & & 44 \\
Co-BPDC & $179.2 / 10$ & & 44 \\
Co-LBDC & & $230.5 / 0.5$ & & 45 \\
Co-LMOF & & $1786 / 1$ & $592 / 20$ & 46 \\
\hline
\end{tabular}


Table S3. Crystal data and structural refinement parameters for compounds 1-3.

\begin{tabular}{|c|c|c|c|}
\hline & 1 & 2 & 3 \\
\hline formula & $\mathrm{C}_{138} \mathrm{H}_{128} \mathrm{Co}_{6} \mathrm{~N}_{12} \mathrm{O}_{34} \mathrm{~S}_{36}$ & $\mathrm{C}_{64} \mathrm{H}_{46} \mathrm{Co}_{5} \mathrm{~N}_{4} \mathrm{O}_{18} \mathrm{~S}_{24}$ & $\mathrm{C}_{22} \mathrm{H}_{24} \mathrm{CoN}_{2} \mathrm{O}_{7} \mathrm{~S}_{6}$ \\
\hline fw & 4006.5 & 2223.3 & 679.8 \\
\hline cryst size $\left(\mathrm{mm}^{3}\right)$ & $0.04 \times 0.08 \times 0.30$ & $0.13 \times 0.15 \times 0.55$ & $0.05 \times 0.07 \times 0.10$ \\
\hline cryst syst & monoclinic & triclinic & monoclinic \\
\hline space group & $P 2_{1} / c$ & $P \overline{1}$ & $P 2_{1} / c$ \\
\hline$a(\AA)$ & $11.6564(13)$ & $7.4395(15)$ & $16.045(4)$ \\
\hline$b(\AA)$ & $29.388(3)$ & $17.175(3)$ & $8.4992(17)$ \\
\hline$c(\AA)$ & $47.199(6)$ & $17.822(4)$ & $25.844(5)$ \\
\hline$\alpha(\operatorname{deg})$ & 90 & $91.19(3)$ & 90 \\
\hline$\beta(\operatorname{deg})$ & $92.119(3)$ & $96.90(3)$ & $124.895(11)$ \\
\hline$\gamma(\operatorname{deg})$ & 90 & $93.44(3)$ & 90 \\
\hline$V\left(\AA^{3}\right)$ & $16157(3)$ & $2255.7(8)$ & $2890.7(11)$ \\
\hline Z & 4 & 1 & 4 \\
\hline$\rho_{\text {calcd }}\left(\mathrm{g} \mathrm{cm}^{-3}\right)$ & 1.639 & 1.635 & 1.553 \\
\hline$F(000)$ & 8128 & 1119 & 1380 \\
\hline$\mu\left(\mathrm{mm}^{-1}\right)$ & 1.144 & 1.518 & 1.070 \\
\hline$T(\mathrm{~K})$ & $223(2)$ & $223(2)$ & $223(2)$ \\
\hline reflns collected & 235249 & 21662 & 26583 \\
\hline unique reflns & 28236 & 11127 & 6609 \\
\hline observed reflns & 18826 & 10137 & 5551 \\
\hline no. params & 2063 & 6125 & 353 \\
\hline GOF on $F^{2}$ & 1.174 & 1.018 & 1.171 \\
\hline$R_{1}[\mathrm{I}>2 \sigma(I)]$ & 0.0929 & 0.0982 & 0.0794 \\
\hline${ }_{W} R_{2} \quad[\mathrm{I}>2 \sigma(I)]$ & 0.1744 & 0.1596 & 0.1771 \\
\hline
\end{tabular}




\section{Equations}

$C_{s p}=\frac{\int_{V_{0}}^{V} I(V) d V}{m v\left(V-V_{0}\right)}$

where $\mathrm{C}_{\mathrm{sp}}\left(\mathrm{F} \mathrm{g} \mathrm{g}^{-1}\right), \mathrm{m}(\mathrm{g}), \mathrm{v}\left(\mathrm{V} \mathrm{s}^{-1}\right),\left(\mathrm{V}^{-} \mathrm{V}_{0}\right)$, and $\mathrm{I}(\mathrm{V})$ are the specific capacitance, mass of the active material, potential scan rate, potential range and current density, respectively.

$C_{s p}{ }_{s p}=\frac{I \times \Delta t}{\Delta V \times m}$

where $\mathrm{C}_{\mathrm{sp}}{ }^{\prime}\left(\mathrm{F} \mathrm{g}^{-1}\right)$ is the discharge specific capacitance, $\mathrm{I}$ is the discharge current (A), $\Delta \mathrm{t}$ is the discharge time (s), $\Delta \mathrm{V}$ is the potential window, and $\mathrm{m}$ is the mass $(\mathrm{g})$ of the active material.

\section{References}

1. Lu, M.; Yuan, X.-P.; Guana, X.-H.; Wang, G.-S. Synthesis of nickel chalcogenide hollow spheres using an L-cysteine-assisted hydrothermal process for efficient supercapacitor electrodes. J. Mater. Chem. A 2017, 5, 3621-3627. 